This article was downloaded by: [Schnakers, Caroline]

On: 26 August 2010

Access details: Access Details: [subscription number 926311163]

Publisher Psychology Press

Informa Ltd Registered in England and Wales Registered Number: 1072954 Registered office: Mortimer House, 3741 Mortimer Street, London W1T 3JH, UK

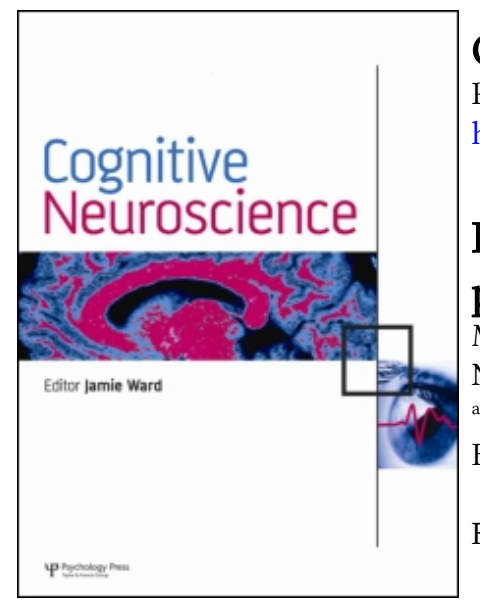

\title{
Cognitive Neuroscience
}

Publication details, including instructions for authors and subscription information:

http://www.informaworld.com/smpp/title content=t909559412

\section{Disorders of consciousness: Moving from passive to resting state and active paradigms}

M. A. Bruno ${ }^{\text {a }}$ A. Soddu ${ }^{\text {a }}$ A. Demertzi ${ }^{\mathrm{a}}$; S. Laureys ${ }^{\mathrm{ab}} ;$ O. Gosseries ${ }^{\mathrm{a}}$; C. Schnakers ${ }^{\mathrm{a}}$; M. Boly ${ }^{\mathrm{a}}$; .

Noirhomme ; M. Thonnard ${ }^{\text {a }}$ C. Chatelle ${ }^{\mathrm{a}}$; A. Vanhaudenhuyse ${ }^{\mathrm{a}}$

${ }^{\mathrm{a}}$ University and University Hospital of Liège, Liège, Belgium ${ }^{\mathrm{b}}$ University Hospital of Liège, Liège,

Belgium

First published on: 02 July 2010

To cite this Article Bruno, M. A. , Soddu, A. , Demertzi, A. , Laureys, S. , Gosseries, O. , Schnakers, C. , Boly, M. ,

Noirhomme, Q. , Thonnard, M. , Chatelle, C. and Vanhaudenhuyse, A.(2010) 'Disorders of consciousness: Moving from passive to resting state and active paradigms', Cognitive Neuroscience, 1: 3, $193-203$, First published on: 02 July 2010 (iFirst)

To link to this Article: DOI: $10.1080 / 17588928.2010 .485677$

URL: http://dx.doi.org/10.1080/17588928.2010.485677

\section{PLEASE SCROLL DOWN FOR ARTICLE}

\footnotetext{
Full terms and conditions of use: http://www.informaworld.com/terms-and-conditions-of-access.pdf

This article may be used for research, teaching and private study purposes. Any substantial or systematic reproduction, re-distribution, re-selling, loan or sub-licensing, systematic supply or distribution in any form to anyone is expressly forbidden.

The publisher does not give any warranty express or implied or make any representation that the contents will be complete or accurate or up to date. The accuracy of any instructions, formulae and drug doses should be independently verified with primary sources. The publisher shall not be liable for any loss, actions, claims, proceedings, demand or costs or damages whatsoever or howsoever caused arising directly or indirectly in connection with or arising out of the use of this material.
} 


\title{
Disorders of consciousness: Moving from passive to resting state and active paradigms
}

\author{
M. A. Bruno ${ }^{1}$, A. Soddu ${ }^{1}$, A. Demertzi ${ }^{1}$, S. Laureys ${ }^{1,2}$, O. Gosseries $^{1}$, C. Schnakers ${ }^{1}$, \\ M. Boly ${ }^{1}$, Q. Noirhomme ${ }^{1}$, M. Thonnard ${ }^{1}$, C. Chatelle ${ }^{1}$, and A. Vanhaudenhuyse ${ }^{1}$ \\ ${ }^{1}$ University and University Hospital of Liège, Liège, Belgium \\ ${ }^{2}$ University Hospital of Liège, Liège, Belgium
}

\begin{abstract}
Following coma, some patients will recover wakefulness without signs of consciousness (i.e., vegetative state) or may show nonreflexive movements but with no ability for functional communication (i.e., minimally conscious state). Currently, there remains a high rate of misdiagnosis of the vegetative state. The increasing use of fMRI and EEG tools permits the clinical characterization of these patients to be improved. We first discuss "resting metabolism" and "passive activation" paradigms, used in neuroimaging and evoked potential studies, which merely identify neural activation reflecting "automatic" processing — that is, occurring without the patient's willful intervention. Secondly, we present an alternative approach consisting of instructing subjects to imagine well-defined sensorymotor or cognitive-mental actions. This strategy reflects volitional neural activation and, hence, witnesses awareness. Finally, we present results on blood-oxgen-level-dependent "default mode network"/resting state studies that might be a promising tool in the diagnosis of these challenging patients.
\end{abstract}

Keywords: Consciousness; Vegetative state; Resting state; fMRI; Active paradigms.

\section{INTRODUCTION}

Following severe brain damage, patients classically evolve through different clinical stages before recovering consciousness. Coma is usually a transient condition that will last no longer than a few days or weeks and is defined as an "unarousable unresponsiveness" (Posner, Saper, Schiff, \& Plum, 2007). After some days or weeks, comatose patients may open their eyes. When this return to "wakefulness" is accompanied by reflexive motor activity only, the condition is called vegetative state (VS; Multi-Society Task Force on PVS, 1994). Many patients in VS regain consciousness in the first month after brain injury. However, if patients show no signs of awareness 1 year after a traumatic brain injury or 3 months after anoxic accident, the chances of recovering functional communication are close to zero and the patient is considered in a permanent VS (Multi-Society Task Force on PVS, 1994). Those who recover from VS typically progress to a minimally conscious state (MCS), which is characterized by minimal but definite behavioral evidence of awareness of self and/or the environment (Giacino et al., 2002). Like the VS, the MCS may be chronic and sometimes permanent. However, at present, no time-windows for "permanent

Correspondence should be addressed to: S. Laureys, Coma Science Group, Cyclotron Research Center, University and University Hospital of Liège, Sart-Tilman B30, Liège, Belgium. E-mail: steven.laureys@ulg.ac.be

M. A. Bruno and A. Soddu contributed equally to the manuscript.

SL is Senior Research Associate; AS, MB and QN are Post-doctoral Fellows; and MAB is Research Fellow at the Fonds de la Recherche Scientifique (FRS). This research was supported by the Fonds de la Recherche Scientifique (FRS), the European Commission (DISCOS, Mindbridge, DECODER, \& CATIA), Concerted Research Action (ARC-06/11-340), The McDonnell Foundation, and The Mind Science Foundation.

(C) 2010 Psychology Press, an imprint of the Taylor \& Francis Group, an Informa business www.psypress.com/cognitiveneuroscience 
MCS" have been agreed upon. Reliable and consistent interactive communication and/or functional use of objects indicate the next boundary in the course of recovery: emergence from MCS (Giacino et al., 2002). Finally, some patients may awake from their coma but be unable to move or speak: the only way they have to express their consciousness is by small eye movements. This state is called locked-in syndrome (LIS) and is characterized by quadriplegia and anarthria with general preservation of cognition (Schnakers et al., 2008a) and an elementary mode of communication that uses vertical or lateral eye movements (American Congress of Rehabilitation Medicine, 1995).

Behavioral assessment is one of the main methods used to detect awareness in severely brain injured patients recovering from coma. Clinical practice shows that recognizing unambiguous signs of conscious perception in such patients can be very challenging. Indeed, behavioral assessment is complicated by the presence of motor/language impairment, tracheotomy, fluctuating arousal level or ambiguous and rapidly habituating responses, which may partly explain the high frequency of misdiagnosis (up to 43\%) in these patients (Schnakers et al., $2009 \mathrm{~b})$. This underestimation of the patient's level of consciousness can also be explained by other factors such as poor expertise in behavioral assessment or the use of insensitive behavioral assessment tools (e.g., using a mirror when evaluating visual pursuit, behavior that is considered as one of the first clinical signs differentiating MCS from VS; Vanhaudenhuyse, Schnakers, Bredart, and Laureys, 2008b). LIS may also be misdiagnosed as coma or VS possibly due to the rarity of this syndrome, the difficulty of recognizing unambiguous signs of consciousness, the fluctuation of vigilance in the acute setting or by additional cognitive or sensory deficits, such as deafness (Bruno et al., 2009; Schnakers et al., 2008a; Smart et al., 2008). Misdiagnosis can lead to grave consequences, especially in end-of-life decision-making. Contrary to patients in VS, those in MCS retain some capacity for cognitive processing (see next section). Moreover, the prognosis of MCS patients is significantly more favorable relative to those in VS (Giacino, 2004a). Clinical attitudes and decisions about end-of-life and pain, therefore, are likely to be influenced by whether one is diagnosed as a VS or a MCS patient (Demertzi et al., 2009). New technical methods offer specific assessment procedures and the possibility to determine objectively whether an unresponsive patient is aware without explicit verbal or motor response. We here review neuroimaging studies using positron emission tomography (PET), functional magnetic resonance imaging (fMRI), and electrophysiological techniques for the assessment of patients with disorders of consciousness, and present new data on resting state brain activity in VS patients.

\section{GLOBAL RESTING METABOLISM}

Using PET, Levy et al. (1987) first showed that patients in a VS suffer from a massive cerebral metabolic reduction, estimated to be $40-50 \%$ of normal values. These results have been repeatedly confirmed by others (Laureys et al., 1999a; Rudolf, Ghaemi, Haupt, Szelies, \& Heiss, 1999; Tommasino, Grana, Lucignani, Torri, \& Fazio, 1995) in VS of different etiologies and duration. In patients with an LIS, overall supratentorial cerebral metabolism has been shown to be preserved partially or fully (Levy et al., 1987), whereas in comatose patients a decrease of $45 \%$ in cerebral metabolism has been observed (Laureys et al., 2001). However, a global depression of cerebral metabolism is not specific to VS or coma only. In slow wave sleep, overall brain metabolism also decreases approximately to $40 \%$ of normal waking values while in REM-sleep metabolism returns to normal values (Maquet et al., 1990). Another example of transient metabolic depression is observed during general anesthesia, which is characterized by comparable reduction in cortical metabolism to that observed in VS (Alkire et al., 1999). However, we have shown that the relationship between global levels of brain function and the presence or absence of awareness is not absolute; rather, some areas in the brain seem more important than others for the emergence of awareness (Laureys, Faymonville, Moonen, Luxen, \& Maquet, 2000c; Laureys et al., 1999a). Indeed, VS patients who subsequently recovered consciousness did not show substantial changes in global metabolic rates for glucose metabolism (Laureys, Lemaire, Maquet, Phillips, \& Franck, 1999b), and some awake healthy volunteers have global brain metabolism values comparable to those observed in some patients in a VS (Laureys, 2005). In VS, a dysfunction was found not in the whole brain but in a wide frontoparietal network encompassing polymodal associative cortices: bilateral lateral frontal regions; parieto-temporal and posterior parietal areas; mesiofrontal, posterior cingulated, and precuneal cortices (Laureys et al., 1999a, 2004a). Posterior cingulate and adjacent precuneal cortices were reported to differentiate MCS from VS patients (Laureys, Owen, \& Schiff, 2004a; intermediate metabolism in MCS, higher than in VS but lower than in conscious 
controls). More recently, a study on patients in the chronic stage of traumatic diffuse brain injury showed a bilateral hypometabolism in the medial prefrontal regions, the medial frontobasal regions, the cingulate gyrus, and the thalamus. At the group level, these regions were more hypometabolic in VS than MCS patients, but MCS still showed less activation than patients who have emerged from this state and who recovered the ability to communicate (Nakayama, Okumura, Shinoda, Nakashima, \& Iwama, 2006). Specifically, awareness seems related not exclusively to the activity in the frontoparietal network but, as importantly, to the functional connectivity within this network and the thalami. Indeed, long-range cortico-cortical and cortico-thalamo-cortical "functional disconnections" could be identified in the VS (Laureys et al., 1999a, 2000b).

\section{PASSIVE PARADIGMS: CEREBRAL ACTIVATION FROM EXTERNAL STIMULATION}

\section{Functional neuroimaging}

Somatosensory, auditory, and visual perceptions are conscious experiences; thus, the wakeful unconsciousness of VS patients, by definition, precludes these experiences. However, the absence of a behavioral response cannot be taken as an absolute proof of the absence of consciousness. Several fMRI activation studies in VS (Coleman et al., 2007; Di et al., 2007; Fernandez-Espejo et al., 2008; Moritz et al., 2001; Staffen, Kronbichler, Aichhorn, Mair, and Ladurner, 2006) have confirmed previous PET studies showing preserved activation of "lower level" primary sensory cortices which are disconnected from "higher order" associative cortical networks employing auditory (Boly et al., 2004; Laureys et al., 2000a; Owen et al., 2002), somatosensory (Boly et al., 2008a), or visual (Menon et al., 1998; Owen et al., 2002) stimulations. Similar studies in PET reported that MCS patients showed a more widespread activation than VS, with a cortico-cortical functional connectivity more efficient in MCS compared to VS (Boly et al., 2004). These results confirmed that MCS patients may experience pain and hence should systematically receive appropriate analgesic treatment. Moreover, stimuli with emotional valence (baby cries and own name) were shown to induce a much more widespread activation than did meaningless noise in the MCS (Laureys et al., 2004b). Stimuli with emotional valence (the voice of the patient's mother compared with an unfamiliar voice) were also shown to activate amygdala in a traumatic MCS patient (Bekinschtein et al., 2004). Similarly, Schiff et al. (2005), in two MCS patients, showed selective activation in components of the cortical language networks during presentation of narratives read by a familiar voice and containing personally meaningful content. Such context-dependent higher-order auditory processing shows that content does matter when talking to MCS patients. Finally, some exceptional VS patients may also show higher atypical level of cortical activation in response to auditory stimulations, and this was proposed to be a surrogate marker of good prognosis (Di et al., 2007).

\section{Event-related potentials}

Event-related potentials (ERPs) have been used for a long time to assess comatose patients. Early components of these potentials arising within $100 \mathrm{~ms}$ are known to persist even in unconscious states. The later components of exogenous potentials and other so-called "endogenous" ERP components (e.g., $\mathrm{P} 300$ ) are more reliably related to the (unconscious or conscious) cognitive processing of the information, and less frequently observed in disorders of consciousness (Vanhaudenhuyse, Laureys, \& Perrin, 2008a). In several studies, ERPs were used to evaluate the integrity of detection of noncommunicative patients' own name, in order to assess the possible preservation of residual linguistic and self-processing in these patients. Differential P300 wave to the own name (as compared to other names) was observed in LIS patients (Perrin et al., 2006), which is not surprising since their cognitive functions and their linguistic comprehension remain preserved (Onofrj, Thomas, Paci, Scesi, and Tombari, 1997; Schnakers et al., 2008a). In MCS, results suggested that the auditory system was relatively preserved in response to passive tones and language stimulation, implying that these patients are able to detect salient words (Perrin et al., 2006). Most surprisingly, some VS patients emitted a differential P300, although delayed as compared to age-matched controls (Perrin et al., 2006). These last results showed that the P300 wave resulting from a passive paradigm is not useful to successfully distinguish unconscious from conscious patients. However, in most studies, the presence of a P300 correlated with favorable outcome in comatose patients (Vanhaudenhuyse et al., 2008a). 


\section{ACTIVE PARADIGMS: COMMAND FOLLOWING IN NONCOMMUNICATIVE PATIENTS}

\section{Functional neuroimaging}

In the absence of a full understanding of the neural correlates of consciousness, even a near-normal activation in response to passive stimulations cannot be considered a proof of the presence of awareness. Instead, all that can be inferred is that a specific brain region is, to some degree, still able to perceive and process relevant sensory stimuli. The question that arises is how we can disentangle automatic from voluntary conscious brain activation. In 2006, Owen et al. addressed this concern by applying an fMRI paradigm in a traumatic VS patient who was asked to perform two mental imagery tasks ("Imagine playing tennis" and "Imaging visiting your house"). Activation was observed in the supplementary motor area after the patient was asked to imagine playing tennis, and in parahippocampal gyrus when she was asked to imagine visiting her house. Similar activation patterns were seen in healthy volunteers (Boly et al., 2007a). Importantly, because the only difference between the conditions that elicited task-specific activation was in the instruction given at the beginning of each scanning session, the activation observed can only reflect the intentions of the patient, rather than some altered property of the outside world. Some could argue that the words "tennis" and "house" may have automatically triggered the patterns of activation observed in target brain areas in this patient in the absence of conscious awareness. Although it is well documented that these words elicit wholly automatic neural responses in the absence of conscious awareness (Hauk, Johnsrude, \& Pulvermuller, 2004), such responses typically last for a few seconds and occur in regions of the brain that are associated with word processing. In this patient, the observed activity persisted for the full $30 \mathrm{~s}$ of each imagery task and persisted until the patient was cued with another stimulus indicating that she should rest. Thus, such responses cannot be explained in terms of automatic brain processes (Soddu et al., 2009). In addition, the responses in the patient were observed not in brain regions that are known to be involved in word processing but, rather, in regions that are known to be involved in the two imagery tasks that she was asked to carry out (Owen et al., 2007). In this sense, the decision to "imagine playing tennis" rather than simply "rest" is an act of willed intention and, therefore, clear evidence for response to command awareness. The results of this study should not be misinterpreted as evidence that all patients in VS may be conscious. Interestingly, when re-examined six months later, the patient showed inconsistent signs of consciousness. The most likely explanation of these results is that the patient was already beginning the transition to the MCS at the time of the experiment. This study also highlights the importance of fMRI as a potentially good marker for both diagnosis and prognosis (Di et al., 2007).

\section{ERPs}

The use of a passive ERP paradigm is not sufficient to reliably disentangle VS from MCS. Indeed, even if passive ERP paradigms can highlight ongoing brain processing for a given stimulus input, they do not differentiate between automatic and voluntary cognitive processes and, therefore, between unconscious and conscious patients. For this reason, an active ERPs paradigm was developed, where the participant is instructed to voluntarily direct attention to a target stimulus and to ignore other stimuli (Figure 1) (Schnakers et al., 2008b, 2009a). Group as well as individual results showed that a larger P300 response to the own name was observed in MCS patients in active condition as compared to passive listening. This P300 amplitude was otherwise equivalent to that observed in controls, while no task-related P300 changes in VS patients were observed (Schnakers et al., 2008b). This suggests that MCS patients were able to voluntarily focus their attention on the target as a function of task requirements. This active ERPs paradigm permitted to detect consciousness in a total LIS patient (i.e., characterized by complete immobility including all eye movements; Bauer, Gerstenbrand, \& Rumpl, 1979) that behaviorally would be diagnosed as comatose (Schnakers et al., 2009a). In a similar way, conscious processing was detected in three out of four MCS patients who were instructed to actively count the number of deviant trials in series of sound, while no response were recorded in VS patients (Bekinschtein et al., 2009).

\section{RESTING STATE FMRI PARADIGM: A NEW TOOL TO CATEGORIZE DISORDERS OF CONSCIOUSNESS PATIENTS?}

Resting state fMRI acquisitions are easy to perform and could have a potentially broader and faster translation into clinical practice. Recent studies on spontaneous fluctuations in the fMRI blood-oxygen-level-dependent (BOLD) signal recorded in "resting" awake healthy subjects showed the presence of coherent fluctuations 

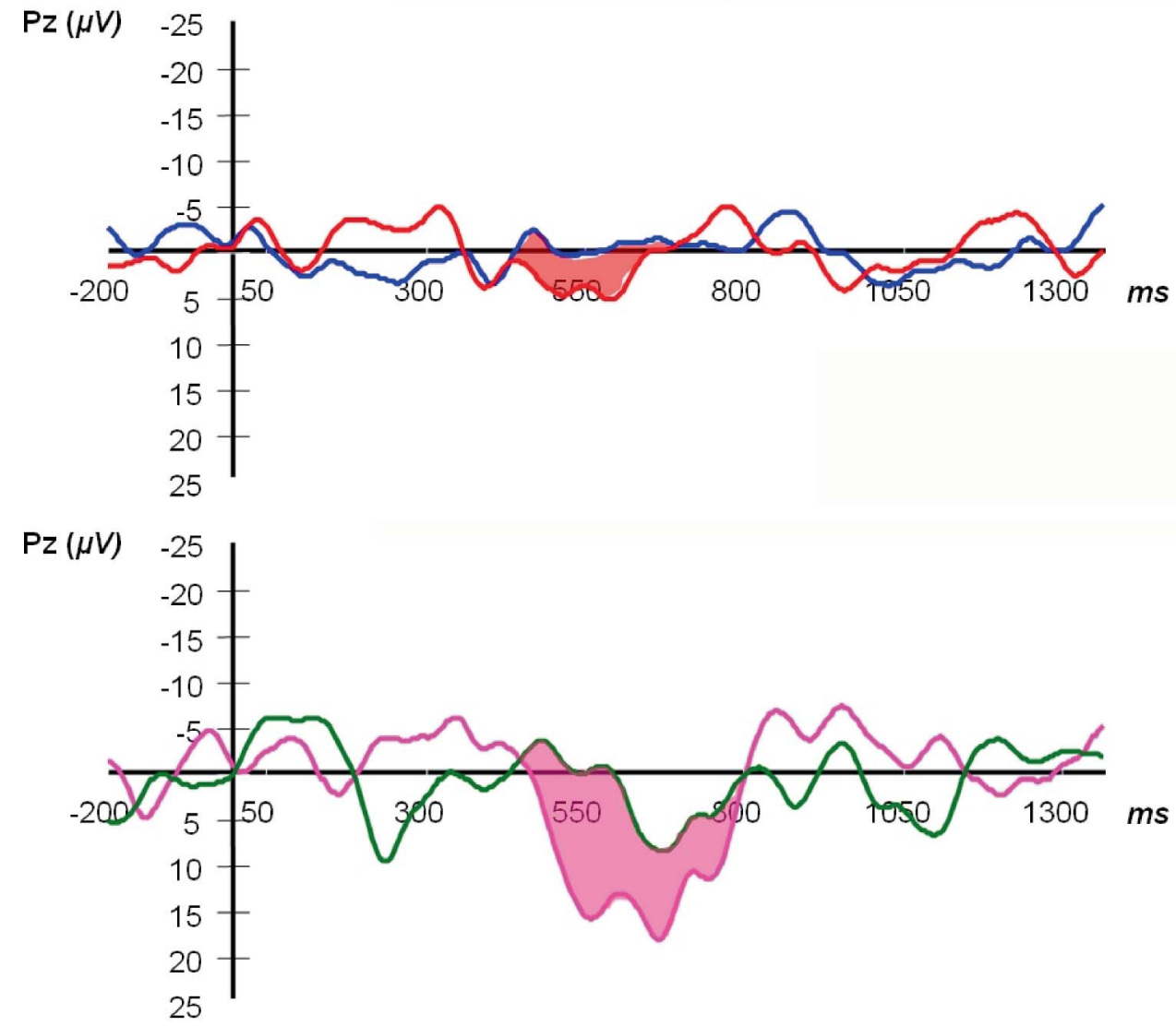

Figure 1. Illustration of active and passive event-related potential paradigms in a 22-year-old locked-in syndrome patient. Upper panel depicts the patient's response to an unfamiliar name (listened nontarget unfamiliar name, in blue) as compared with active condition (responded to target unfamiliar name, in red). Lower panel depicts the patient's own-name response in the passive condition (listened nontarget own name, in green) and in the active condition (responded to target own name, in pink). (Adapted from data in Schnakers et al., 2009a.)

among functionally defined neuroanatomical networks (Boly et al., 2008b; Raichle, 2006). The concept of a "default mode network" describes a set of brain areas exhibiting task-induced deactivations, encompassing precuneus, posterior parietal lobe, and medial prefrontal cortex, which are more active at rest than when we are involved in attention-demanding cognitive tasks (Raichle et al., 2001). The clinical interest of default network MRI studies is that they allow the investigation of higher order cognitive networks without requiring patients' active participation, particularly important in VS and MCS. We here compared default mode network in VS and brain-dead patients with healthy volunteers.

\section{Patients}

We first created a healthy control template of the default mode network (DMN) by analyzing 11 volunteers (age range 21-60 years; 4 women). Secondly, we compared 4 brain injured patients (3 vegetative:
1 ischemia, 1 encephalopathy, 1 traumatic; and 1 hemorrhagic brain-dead patients (published in Boly et al., 2009), age range 27-77 years, all men) to 9 other healthy volunteers (age range 29-65 years, 5 women). In patients, clinical examination was repeatedly performed using standardized scales (the Coma Recovery Scale Revised, Giacino Kalmar, \& Whyte, 2004b; and the Glasgow Liege scale, Born, 1988) on the day of scanning, and in the week before and the week after. Patients were scanned in an unsedated condition. The study was approved by the Ethics Committee of the Medical School of the University of Liège. Informed consent to participate to the study was obtained from the subjects themselves in the case of healthy subjects, and from the legal surrogates of the patients.

\section{Data acquisition and analysis}

In all participants, resting state BOLD data were acquired on a $1.5 \mathrm{~T}$ MR scanner (Symphony Tim, 
Siemens, Germany) with a gradient echo-planar sequence using axial slice orientation (36 slices; voxel size $=3.75 \times 3.75 \times 3.6 \mathrm{~mm}^{3} ;$ matrix size $=64 \times 64 \times$ 36 ; repetition time $=3000 \mathrm{~ms}$; echo time $=30 \mathrm{~ms}$; flip angle $=90^{\circ}$; field of view $=240 \mathrm{~mm}$ ). A protocol of 200 scans with a duration of $10 \mathrm{~min}$ was performed. fMRI data were preprocessed using BrainVoyager software (R. Goebel, Brain Innovation, Maastricht, The Netherlands). Preprocessing of functional scans included 3D motion correction, linear trend removal, slice scan time correction, and filtering out of low frequencies of up to $0.005 \mathrm{~Hz}$. The data were spatially smoothed with a Gaussian filter of full width at half maximum value of $8 \mathrm{~mm}$. Independent component analysis (ICA) was performed with BrainVoyager using 30 components (Ylipaavalniemi \& Vigario, 2008). An average template DMN map was calculated on 11 healthy subjects. We performed, as implemented in BrainVoyager (self-organizing ICA; Esposito et al., 2005), a spatial similarity test on single subjects independent components (IC) and we averaged the maps of the ICs belonging to the same cluster. The cluster corresponding to the DMN was selected by visual inspection. In order to select the DMN for each subject and patient, we run self-organizing ICA with the average ICs coming from the 11 healthy subjects template and we picked the component clustering with the DMN template (spatial similarity test). Self-organizing ICA could assign a similarity value that indicates how well the selected IC fitted the average DMN map based on the 11 subjects (the similarity test was based only on spatial properties without excluding components with a power spectrum dominated by high frequency). The same protocol of 200 scans was acquired on a spherical phantom. Finally, a two-tailed unequal variance Student $t$-test compared the spatial similarity values of the selected DMN map in healthy controls compared to VS patients. Three motion indices were introduced describing the motion of patients compared to healthy controls: the mean frequency calculated as the mean of the frequency of each motion curve (three translations and three rotations), the mean over time of the full displacement during the acquisition calculated as the square root of the sum of the squares of the six motion parameters, and the mean over time of the displacement speed during the acquisition calculated as the square root of the sum of the squares of the six motion parameters variation over one time unit (repetition time).

\section{RESULTS}

A healthy controls mean spatial map identified the DMN pattern (Figure 2a) showing full overlap with the template identified by the black and white contour. The principal brain regions characterizing the DMN, posterior cingulate/precuneal, mesiofrontal and posterior parietal cortices, were detected. Compared to controls, VS patients showed a significant lower spatial similarity $(0.47 \pm 0.08$, range $0.33-0.55$ vs. $0.23 \pm 0.12$, range $0.12-0.35 ; p=.05$ ). The brain-dead patient (and the phantom) also showed lower spatial similarity compared to controls with values in the VS range. Finally, none of the VS patients showed a DMN with a spatial pattern comparable with healthy controls (Figure $2 b-d$ ), as assessed by visual inspection, even if in the case of V1 the spatial similarity had a value consistent with healthy subjects (Table 1). Rapid transient "clonic" motions (i.e., spasmodic changes of muscular contraction) were observed for VS1 and VS3 as also confirmed by spatial maps' periphery patterns. The brain-dead patient didn't show any significant spatial pattern, confirming results of Boly and collaborators (2009).

\section{DISCUSSION}

After creating a template of the DMN, we identified the DMN at the single subject level, in a user-independent manner. In healthy volunteers, the identified component showed the typical spatial pattern of the DMN (Beckmann, DeLuca, Devlin, \& Smith, 2005). In VS patients, as well as in the brain-dead, we failed to show any consistent pattern of DMN, even if single subjects brain activation maps showed residual connectivity in VS. In our view, these residual connectivity patterns are not reflecting residual DMN neuronal activity but could be explained by movement artifacts. Cardiorespiratory and vascular effects could also be a source of artifactual connectivity. BOLD signal changes within regions of the DMN have been found to be reduced after correcting for cardiorespiratory effects (van Buuren et al., 2009). In addition, it should be stressed that altered blood flow and physiology, such as neurovascular decoupling, could also effect the BOLD signal detected in fMRI (Logothetis, Pauls, Augath, Trinath, \& Oeltermann, 2001), especially in the context of traumatic and ischemic encephalopathy. This of course cannot exclude the absence of neural activity in these patients (Boly et al., 2009; van Buuren et al., 2009). Boly and collaborators (2009) showed that correlations with posterior cingulate cortex are reduced in one VS as compared to agematched controls, and argued that this reduced functional connectivity within the DMN in VS was in line with the hypothesis that spontaneous fMRI signal changes may be partly related to ongoing interoceptive states of mind or conscious thoughts. 

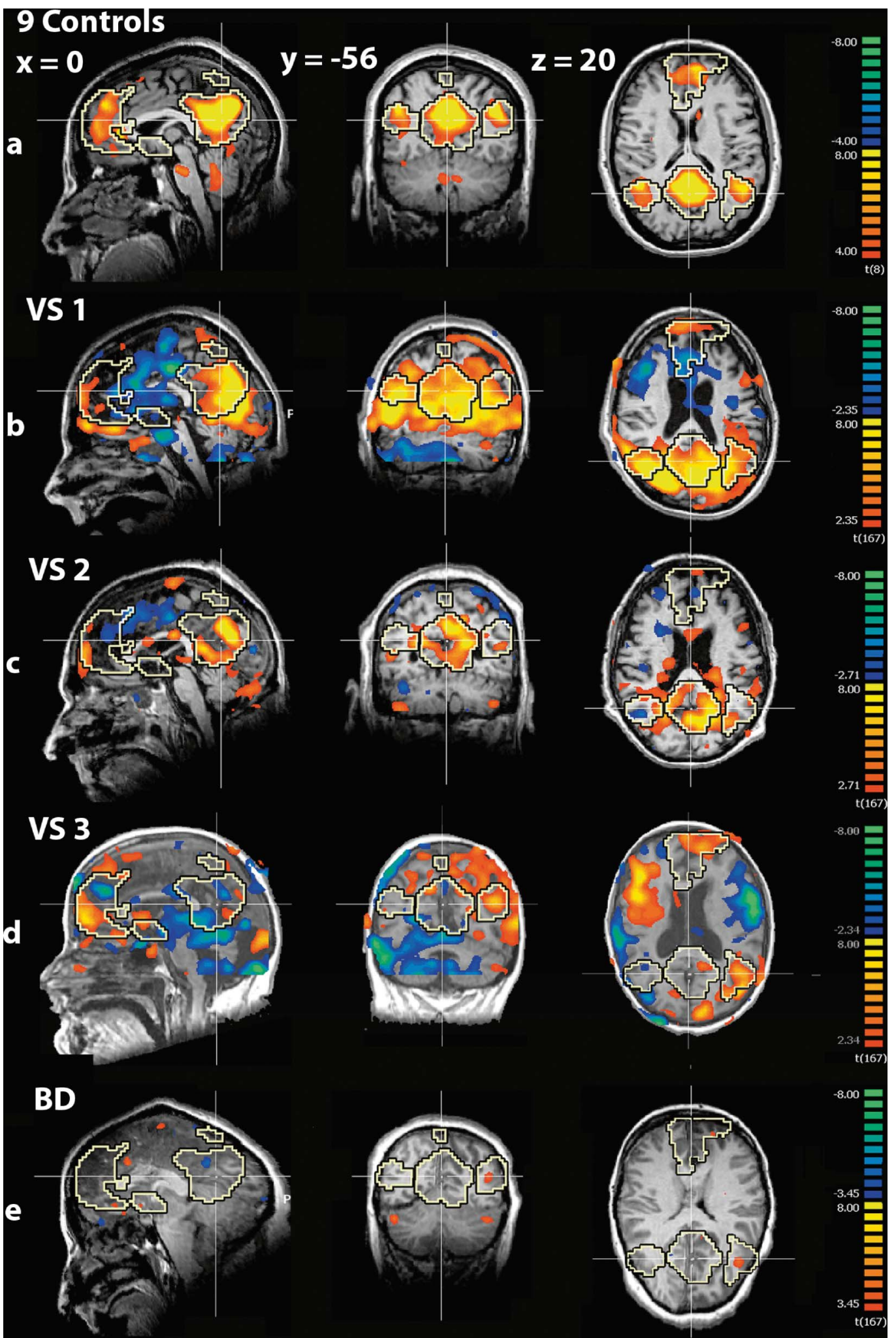

Figure 2. Resting state EPI-BOLD acquisition in (a) 9 healthy volunteers, with a spatial map obtained by running a random effect group GLM analysis using as predictors the time courses of the ICs selected as default mode (thresholded at false discovery rate corrected $p<.05$ ) within default mode mask obtained from an independent dataset (the 11 healthy controls for the independent study) shown as black and white contour volume of interest. (b-d) 3 vegetative patients and (e) 1 brain death with spatial maps obtained by running a GLM analysis using as predictor the time courses of the ICs selected as default mode (thresholded at false discovery rate corrected $p<.05$ ). 
TABLE 1

Spatial and temporal properties of the independent component selected as default mode (DM) from resting state fMRI in healthy controls, vegetative (VS) and one brain death (BD) patients (phantom is added for comparison)

\begin{tabular}{|c|c|c|c|c|c|c|}
\hline & $\begin{array}{c}\text { Spatial } \\
\text { similarity }\end{array}$ & $\begin{array}{c}\text { Normalized } \\
\text { variation of } \\
\text { spatial similarity }\end{array}$ & $\begin{array}{c}\text { DM time } \\
\text { course mean } \\
\text { frequency }(\mathrm{Hz})\end{array}$ & $\begin{array}{c}\text { Motion } \\
\text { curves mean } \\
\text { frequency }(\mathrm{Hz})\end{array}$ & $\begin{array}{c}\text { Mean } \\
\text { displacement }\end{array}$ & Mean speed \\
\hline Control 1 & 0.33 & 1.5 & 0.04 & 0.03 & 0.6 & 0.04 \\
\hline Control 2 & 0.51 & 2.9 & 0.05 & 0.06 & 0.3 & 0.14 \\
\hline Control 3 & 0.37 & 1.8 & 0.05 & 0.03 & 1.7 & 0.09 \\
\hline Control 4 & 0.50 & 2.8 & 0.05 & 0.06 & 0.4 & 0.14 \\
\hline Control 5 & 0.54 & 3.2 & 0.07 & 0.05 & 0.8 & 0.25 \\
\hline Control 6 & 0.39 & 2 & 0.04 & 0.04 & 0.3 & 0.02 \\
\hline Control 7 & 0.55 & 3.2 & 0.05 & 0.03 & 3.0 & 0.09 \\
\hline Control 8 & 0.54 & 3.2 & 0.05 & 0.04 & 0.3 & 0.03 \\
\hline Control 9 & 0.47 & 2.6 & 0.04 & 0.03 & 0.8 & 0.05 \\
\hline VS 1 & 0.35 & 1.7 & 0.04 & 0.05 & 1.1 & 0.14 \\
\hline VS 2 & 0.23 & 0.8 & 0.07 & 0.05 & 0.2 & 0.28 \\
\hline VS 3 & 0.12 & -0.1 & 0.04 & 0.03 & 5.9 & 0.50 \\
\hline BD & 0.13 & 0 & 0.07 & 0.06 & 0.1 & 0.27 \\
\hline Phantom & 0.12 & -0.1 & 0.06 & 0.03 & 0.1 & 0.24 \\
\hline
\end{tabular}

Notes: Spatial similarity with an average-template-default mode based on an independent 11 healthy controls data set, normalized variation of spatial similarity (Sim) respect to the brain death (BD) (Sim_subject-Sim_BD)/Sim_BD), and default mode time course mean frequency. Motion properties (means calculated from the six motion curves). Rapid transient "clonic" motions were observed for two of the three patients (VS1 and VS3) as also confirmed by spatial maps periphery patterns, while a drift (i.e., a displacement with low speed) is observed for control 3 and 7.

Motion, pulse, and respiratory artifacts remain a very important problem to tackle to be able to properly assess patients with disorders of consciousness. If recording heart and respiratory rates during the acquisition can help in disentangling neuronal activity from pulse and respiratory artifacts (Gray et al., 2009), further investigations are needed to disentangle effects of motion and neuronal activity in the BOLD signal. In the brain-dead patient, who fulfilled all the standard clinical criteria for brain death (previously published in Boly et al., 2009), fMRI results did not show any long-range significant functional connectivity, confirming that the origin of the BOLD signal was fully due to motion artifacts as expected due to the complete absence of neuronal activity in brain death. Finally, future work should study the relationship between structural and functional connectivity changes in noncommunicative brain-damaged patients. Functional connectivity in DMN has indeed been related to underlying structural anatomy (Greicius, Supekar, Menon, \& Dougherty, 2009). Further multimodal studies should combine resting state fMRI data with structural MRI (e.g. diffusion tensor imaging data).

\section{CONCLUSION}

Patients with disorders of consciousness represent a major clinical problem in terms of clinical assessment, treatment, and daily management. The nonresponsiveness of such patients implies that they can only be diagnosed by means of exclusion criteria such as "no goal-directed eye movements" or "no execution of commands." Those behavioral signs may be very slight and short-term and performance may fluctuate. Integration of neuroimaging and ERPs techniques should improve our ability to disentangle diagnostic and prognostic differences on the basis of underlying mechanisms and better guide our clinical therapeutic options in these challenging patients. A step-by-step approach combining multimodal assessment techniques (i.e., PET scan, fMRI, and ERPs) seems to be appropriate to detect signs of consciousness (Figure 3). Resting metabolism and passive paradigms studies increased our understanding of residual cerebral processing of VS and MSC patients. Active paradigms seem to provide an objective valuable additional diagnostic tool in cases of patients with atypical activation, leading to persisting doubts in clinical diagnosis. Negative results, however, must be cautiously interpreted in case of patients with severely altered level of vigilance, which could present only transient activity in response to the presentation of instructions. Passive and active fMRI paradigms were also shown to potentially be a useful tool to predict possibility of recovery.

Finally, results on the DMN seem promising to distinguish patients with disorders of consciousness by evaluating preservation of connectivity in this resting state network. However, future studies are needed to give a full characterization of default mode connectivity in VS and MCS patients and its potential use in outcome prediction. Future clinical studies should also perform 
CEREBRAL METABOLISM (fMRI - PET scan)

Identification of Spontaneous "Resting" Brain Activity (stimulus independent)
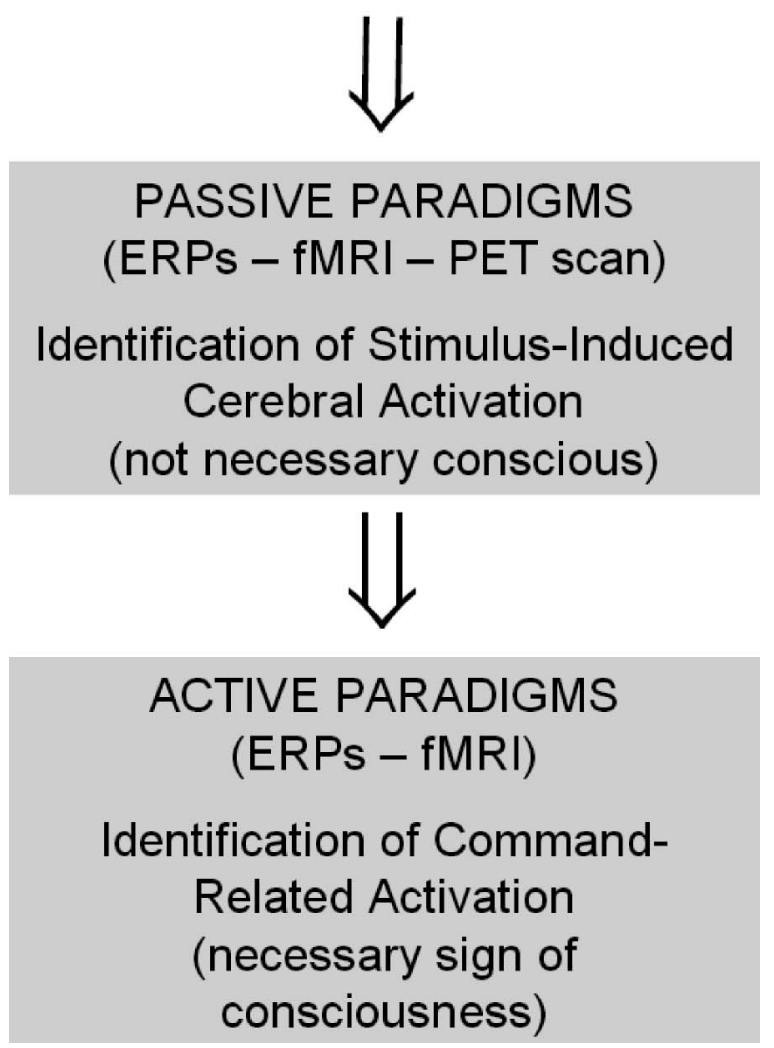

Figure 3. Illustration of a step-by-step approach combining PET scan, ERPs, and fMRI techniques which might reveal signs of consciousness that are unattainable by bedside clinical assessment of disorders of consciousness patients. These high-tech devices might permit some of these patients to show their consciousness by following commands (e.g., to imagine playing tennis, respond to own name) via nonmotor pathways.

heart rate and respiratory rate recording and simultaneous real movement monitoring, which would improve default mode analyses.

\section{REFERENCES}

Alkire, M. T., Pomfrett, C. J., Haier, R. J., Gianzero, M. V., Chan, C. M., Jacobsen, B. P., et al. (1999). Functional brain imaging during anesthesia in humans: Effects of halothane on global and regional cerebral glucose metabolism. Anesthesiology, 90(3), 701-709.
American Congress of Rehabilitation Medicine (1995). Recommendations for use of uniform nomenclature pertinent to patients with severe alterations of consciousness. Archives of Physical Medicine and Rehabilation, 76, 205-209.

Bauer, G., Gerstenbrand, F., \& Rumpl, E. (1979). Varieties of the locked-in syndrome. Journal of Neurology, 221(2), 77-91.

Beckmann, C. F., DeLuca, M., Devlin, J. T., \& Smith, S. M., (2005). Investigations into resting-state connectivity using independent component analysis. Philosophical Transactions of the Royal Society of London B: Biological Sciences, 360, 1001-1013.

Bekinschtein, T., Niklison, J., Sigman, L., Manes, F., Leiguarda, R., Armony, J., et al. (2004). Emotion processing in the minimally conscious state. Journal of Neurology, Neurosurgery \& Psychiatry, 75(5), 788.

Bekinschtein, T., Dehaene, S., Rohaut, B., Tadel, F., Cohen, L., \& Naccache, L. (2009). Neural signature of the conscious processing of auditory regularities. Proceedings of the National Academy of Sciences of the United States of America, 106(5), 1672-1677.

Boly, M., Coleman, M. R., Davis, M. H., Hampshire, A., Bor, D., Moonen, G., et al. (2007a). When thoughts become action: An fMRI paradigm to study volitional brain activity in non-communicative brain injured patients. NeuroImage, 36(3), 979-992.

Boly, M., Faymonville, M. E., Peigneux, P., Lambermont, B., Damas, P., Del Fiore, G., et al. (2004). Auditory processing in severely brain injured patients: Differences between the minimally conscious state and the persistent vegetative state. Archives of Neurology, 61(2), 233-238.

Boly, M., Faymonville, M. E., Schnakers, C., Peigneux, P., Lambermont, B., Phillips, C., et al. (2008a). Perception of pain in the minimally conscious state with PET activation: An observational study. Lancet Neurology, 7(11), 1013-1020.

Boly, M., Phillips, C., Tshibanda, L., Vanhaudenhuyse, A., Schabus, M., Dang-Vu, T. T., et al. (2008b). Intrinsic brain activity in altered states of consciousness: How conscious is the default mode of brain function? Annals of the New York Academy of Sciences, 1129, 119-129.

Boly, M., Tshibanda, L., Vanhaudenhuyse, A., Noirhomme, Q., Schnakers, C., Ledoux, D., et al. (2009). Functional connectivity in the default network during resting state is preserved in a vegetative but not in a brain dead patient. Human Brain Mapping, 30(8), 2393-2400.

Born, J. D. (1988). The Glasgow-Liège Scale: Prognostic value and evaluation of motor response and brain stem reflexes after severe head injury. Acta Neurochirurgica, 95, 49-52.

Bruno, M. A., Schnakers, C., Damas, F., Pellas, F., Lutte, I., Bernheim, J., et al. (2009). Locked-in syndrome in children: Report of five cases and review of the literature. Pediatric Neurology, 41(4), 237-246.

Coleman, M. R., Rodd, J. M., Davis, M. H., Johnsrude, I. S., Menon, D. K., Pickard, J. D., et al. (2007). Do vegetative patients retain aspects of language comprehension? Evidence from fMRI. Brain, 130(10), 2494-2507.

Dehaene, S., \& Naccache, L. (2001). Towards a cognitive neuroscience of consciousness: Basic evidence and a workspace framework. Cognition, 79(1-2), 1-37. 
Demertzi, A., Schnakers, C., Ledoux, D., Chatelle, C., Bruno, M. A., Vanhaudenhuyse, A., et al. (2009). Different beliefs about pain perception in the vegetative and minimally conscious states: A European survey of medical and paramedical professionals. Progress in Brain Research, 177, 329-338.

Di, H. B., Yu, S. M., Weng, X. C., Laureys, S., Yu, D., Li, J. Q., et al. (2007). Cerebral response to patient's own name in the vegetative and minimally conscious states. Neurology, 68(12), 895-899.

Esposito, F., Scarabino, T., Hyvarinen, A., Himberg, J., Formisano, E., Comani, S., et al. (2005). Independent component analysis of fMRI group studies by selforganizing clustering. NeuroImage, 25, 193-205.

Fernandez-Espejo, D., Junque, C., Vendrell, P., Bernabeu, M., Roig, T., Bargallo, N., et al. (2008). Cerebral response to speech in vegetative and minimally conscious states after traumatic brain injury. Brain Injury, 22(11), 882-890.

Giacino, J. T. (2004a). The vegetative and minimally conscious states: Consensus-based criteria for establishing diagnosis and prognosis. NeuroRehabilitation, 19(4), 293-298.

Giacino, J. T., Kalmar, K., \& Whyte, J. (2004b). The JFK Coma Recovery Scale - Revised: Measurement characteristics and diagnostic utility. Archives of Physical and Medical Rehabilitation, 85(12), 2020-2029.

Giacino, J. T., Ashwal, S., Childs, N., Cranford, R., Jennett, B., Katz, D. I., et al. (2002). The minimally conscious state: Definition and diagnostic criteria. Neurology, 58(3), 349-353.

Gray, M. A., Minati, L., Harrison, N. A., Gianaros, P. J., Napadow, V., \& Critchley, H. D. (2009). Physiological recordings: Basic concepts and implementation during functional magnetic resonance imaging. NeuroImage, 47, 1105-1115.

Greicius, M. D., Supekar, K., Menon, V., \& Dougherty, R. F. (2009). Resting-state functional connectivity reflects structural connectivity in the default mode network. Cerebral Cortex, 19, 72-78.

Hauk, O., Johnsrude, I., \& Pulvermuller, F. (2004). Somatotopic representation of action words in human motor and premotor cortex. Neuron, 41(2), 301-307.

Kwong, K. K., Belliveau, J. W., Chesler, D. A., Goldberg, I. E., Weisskoff, R. M., Poncelet, B. P., et al. (1992). Dynamic magnetic resonance imaging of human brain activity during primary sensory stimulation. Proceedings of the National Academy of Sciences of the United States of America, 89, 5675-5679.

Laureys, S. (2005). The neural correlate of (un)awareness: Lessons from the vegetative state. Trends in Cognitive Sciences, 9(12), 556-559.

Laureys, S., Berré, J., \& Goldman, S. (2001). Cerebral function in coma, vegetative state, minimally conscious state, locked-in syndrome and brain death. In J. L. Vincent (Ed.), 2001 Yearbook of intensive care and emergency medicine. (pp. 386-396). Berlin: Springer-Verlag.

Laureys, S., Faymonville, M. E., Degueldre, C., Fiore, G. D., Damas, P., Lambermont, B., et al. (2000a). Auditory processing in the vegetative state. Brain, 123(8), 15891601.

Laureys, S., Faymonville, M. E., Luxen, A., Lamy, M., Franck, G., \& Maquet, P. (2000b). Restoration of tha- lamocortical connectivity after recovery from persistent vegetative state. Lancet, 355(9217), 1790-1791.

Laureys, S., Faymonville, M. E., Moonen, G., Luxen, A., \& Maquet, P. (2000c). PET scanning and neuronal loss in acute vegetative state. Lancet, 355, 1825-1826.

Laureys, S., Goldman, S., Phillips, C., Van Bogaert, P., Aerts, J., Luxen, A., et al. (1999a). Impaired effective cortical connectivity in vegetative state. NeuroImage, 9(4), 377-382.

Laureys, S., Lemaire, C., Maquet, P., Phillips, C., \& Franck, G. (1999b). Cerebral metabolism during vegetative state and after recovery to consciousness. Journal of Neurology, Neurosurgery \& Psychiatry, 67(1), 121.

Laureys, S., Owen, A. M., \& Schiff, N. D. (2004a). Brain function in coma, vegetative state, and related disorders. Lancet Neurology, 3(9), 537-546.

Laureys, S., Perrin, F., Faymonville, M. E., Schnakers, C., Boly, M., Bartsch, V., et al. (2004b). Cerebral processing in the minimally conscious state. Neurology, 63(5), 916-918.

Levy, D. E., Sidtis, J. J., Rottenberg, D. A., Jarden, J. O., Strother, S. C., Dhawan, V., et al. (1987). Differences in cerebral blood flow and glucose utilization in vegetative versus locked-in patients. Annals of Neurology, 22(6), 673-682.

Logothetis, N. K., Pauls, J., Augath, M., Trinath, T., \& Oeltermann, A. (2001). Neurophysiological investigation of the basis of the fMRI signal. Nature, 412, 150-157.

Maquet, P., Dive, D., Salmon, E., Sadzot, B., Franco, G., Poirrier, R., et al. (1990). Cerebral glucose utilization during sleep-wake cycle in man determined by positron emission tomography and [18F]2-fluoro-2-deoxy-D-glucose method. Brain Research, 513(1), 136-143.

Menon, D. K., Owen, A. M., Williams, E. J., Minhas, P. S., Allen, C. M., Boniface, S. J., et al. (1998). Cortical processing in persistent vegetative state. Lancet, 352(9123), 200.

Moritz, C. H., Rowley, H. A., Haughton, V. M., Swartz, K. R., Jones, J., \& Badie, B. (2001). Functional MR imaging assessment of a non-responsive brain injured patient. Magnetic Resonance Imaging, 19(8), 1129-1132.

Multi-Society Task Force on PVS, The (1994). Medical aspects of the persistent vegetative state (1). New England Journal of Medicine, 330(21), 1499-1508.

Nakayama, N., Okumura, A., Shinoda, J., Nakashima, T., \& Iwama, T. (2006). Relationship between regional cerebral metabolism and consciousness disturbance in traumatic diffuse brain injury without large focal lesions: An FDG-PET study with statistical parametric mapping analysis. Journal of Neurology, Neurosurgery \& Psychiatry, 77(7), 856-862.

Onofrj, M., Thomas, A., Paci, C., Scesi, M., \& Tombari, R. (1997). Event related potentials recorded in patients with locked-in syndrome. Journal of Neurology, Neurosurgery \& Psychiatry, 63(6), 759-764.

Owen, A., Coleman, M., Boly, M., Davis, M., Laureys, S., Jolles, J., et al. (2007). Response to comments on "Detecting awareness in the vegetative state". Science, 315(5816), 1221.

Owen, A. M., Coleman, M. R., Boly, M., Davis, M. H., Laureys, S., \& Pickard, J. D. (2006). Detecting awareness in the vegetative state. Science, 313(5792), 1402.

Owen, A. M., Menon, D. K., Johnsrude, I. S., Bor, D., Scott, S. K., Manly, T., et al. (2002). Detecting residual cognitive function in persistent vegetative state. Neurocase, 8(5), 394-403. 
Perrin, F., Schnakers, C., Schabus, M., Degueldre, C., Goldman, S., Bredart, S., et al. (2006). Brain response to one's own name in vegetative state, minimally conscious state, and locked-in syndrome. Archives of $\mathrm{Neu}$ rology, 63(4), 562-569.

Posner, J., Saper, C., Schiff, N., \& Plum, F. (2007). Plum and Posner's diagnosis of stupor and coma. New York: Oxford University Press.

Raichle, M. E. (2006). Neuroscience: The brain's dark energy. Science, 314(5803), 1249-1250.

Raichle, M. E., MacLeod, A. M., Snyder, A. Z., Powers, W. J., Gusnard, D. A., \& Shulman, G. L. (2001). A default mode of brain function. Proceedings of the National Academy of Sciences of the United States of America, 98(2), 676-682.

Rudolf, J., Ghaemi, M., Haupt, W. F., Szelies, B., \& Heiss, W. D. (1999). Cerebral glucose metabolism in acute and persistent vegetative state. Journal of Neurosurgical Anesthesiology, 11(1), 17-24.

Schiff, N. D., Rodriguez-Moreno, D., Kamal, A., Kim, K. H., Giacino, J. T., Plum, F., et al. (2005). fMRI reveals large-scale network activation in minimally conscious patients. Neurology, 64(3), 514-523.

Schnakers, C., Majerus, S., Goldman, S., Boly, M., Van Eeckhout, P., Gay, S., et al. (2008a). Cognitive function in the locked-in syndrome. Journal of Neurology, 255(3), 323-330.

Schnakers, C., Perrin, F., Schabus, M., Hustinx, R., Majerus, S., Moonen, G., et al. (2009a). Detecting consciousness in a total locked-in syndrome: An active eventrelated paradigm. Neurocase, 15, 271-277.

Schnakers, C., Perrin, F., Schabus, M., Majerus, S., Ledoux, D., Damas, P., et al. (2008b). Voluntary brain processing in disorders of consciousness. Neurology, 71, 1614-1620.

Schnakers, C., Vanhaudenhuyse, A., Giacino, J., Ventura, M., Boly, M., Majerus, S., et al. (2009b). Diagnostic accuracy of the vegetative and minimally conscious state: Clinical consensus versus standardized neurobehavioral assessment. BMC Neurology, 9, 35.

Smart, C. M., Giacino, J. T., Cullen, T., Moreno, D. R., Hirsch, J., Schiff, N. D., et al. (2008). A case of locked-in syndrome complicated by central deafness. Nature Clinical Practice Neurology, 4(8), 448-453.

Soddu, A., Boly, M., Nir, Y., Noirhomme, Q., Vanhaudenhuyse, A., Demertzi, A., et al. (2009). Reaching across the abyss: Recent advances in functional magnetic resonance imaging and their potential relevance to disorders of consciousness. Progress in Brain Research, 177, 261-74.

Staffen, W., Kronbichler, M., Aichhorn, M., Mair, A., \& Ladurner, G. (2006). Selective brain activity in response to one's own name in the persistent vegetative state. Journal of Neurology, Neurosurgery \& Psychiatry, 77(12), 1383-1384.

Tommasino, C., Grana, C., Lucignani, G., Torri, G., \& Fazio, F. (1995). Regional cerebral metabolism of glucose in comatose and vegetative state patients. Journal of Neurosurgical Anesthesiology, 7(2), 109-116.

van Buuren, M., Gladwin, T. E., Zandbelt, B. B., van den Heuvel, M., Ramsey, N. F., Kahn, R. S., et al. (2009). Cardiorespiratory effects on default-mode network activity as measured with fMRI. Human Brain Mapping, 30(9), 3031-3042.

Vanhaudenhuyse, A., Laureys, S., \& Perrin, F. (2008a). Cognitive event-related potentials in comatose and postcomatose states. Neurocritical Care, 8(2), 262-270.

Vanhaudenhuyse, A., Schnakers, C., Bredart, S., \& Laureys, S. (2008b). Assessment of visual pursuit in post-comatose states: Use a mirror. Journal of Neurology, Neurosurgery \& Psychiatry, 79(2), 223.

Ylipaavalniemi, J., \& Vigario, R. (2008). Analyzing consistency of independent components: An fMRI illustration. NeuroImage 39, 169-180. 